\title{
A Microstructural Study of Alloy 718 Plus $^{\text {TM }}$ \\ John F. Radavich ${ }^{1}$ and Tadev Carneiro ${ }^{2}$ Micro-Met Laboratories, Inc. 209 North Street, W. Lafayette, IN 47906 Reference Metals Company, Inc. 1000 Old Pond Road, Bridgeville, PA 15017
}

\begin{abstract}
A microstructural study using metallographic, x-ray diffraction, and Edax analyses techniques was carried out on alloy 718 Plus samples which were in various thermal conditions. Results of this study showed that the strengthening phase is gamma prime which grows larger with increasing time of exposure. A delta phase nucleates and grows as the gamma prime phase becomes larger. No gamma double prime is found in the standard heat treatment and no $\alpha \mathrm{Cr}$, sigma or $\mathrm{Cr}$ carbides are found in samples exposed for 2500 hours at $732^{\circ} \mathrm{C}\left(1350^{\circ} \mathrm{F}\right)$ in Alloy 718 plus while $\alpha \mathrm{Cr}$ forms in as little as 1000 hours at $704^{\circ} \mathrm{C}$ in Alloy 718 .
\end{abstract}

\section{Introduction}

Alloy 718 has been the work horse in the gas turbine field for the past 50 years. As disk temperatures keep rising, alloy 718 which is currently the alloy becomes temperature limited to $650^{\circ} \mathrm{C}$ as its strength drops due to the transitional changes in the gamma double prime and gamma prime to delta and $\alpha \mathrm{Cr}$ phases.

A new alloy has been developed by Allvac called alloy $718 \mathrm{Plus}^{\mathrm{TM}}$ which is claimed to have a $55^{\circ} \mathrm{C}\left(100^{\circ} \mathrm{F}\right)$ higher temperature capability than alloy $718(1)$. The major changes in its composition from alloy 718 are the substitution of $10 \% \mathrm{Co}$ for $10 \% \mathrm{Fe}$ and a three fold increase in the $\mathrm{Al}$ content. The resultant strengthening phase is reported to be gamma prime $\left(\gamma^{\prime}\right)$ rather than double gamme prime $\left(\gamma^{\prime \prime}\right)(1)$

Because the $\mathrm{Cr}$ content remains at $18 \%$ and the continual formation of $\gamma^{\prime}$ depletes $\mathrm{Ni}$ from the matrix, there exists the possibility of the formation of $\mathrm{Cr}$ rich phases such as $\alpha \mathrm{Cr}$, sigma or $\mathrm{Cr}$ carbides and a loss of stability with long exposures. The objectives of this study are two-fold: (1) describe an optimum sample preparation for alloy 718 Plus, and (2) determine the phase behavior of alloy 718 Plus as it relates to the phase behavior in alloy 718 .

\section{Samples Studied}

A group of alloy 718 Plus $^{\mathrm{TM}}$ samples were received from Allvac with thermal treatments ranging from $982^{\circ} \mathrm{C} / 4$ hours to standard heat treatment and exposures of 2500 hours at $732^{\circ} \mathrm{C}$ $\left(1350^{\circ} \mathrm{F}\right)$. The samples selected for study and their thermal histories are given in Table 1 .

\section{Sample}

1.

2. As heat treated

3. As heat treated plus

4. As heat treated plus

5. As heat treated plus
Table 1.

Thermal History
$982^{\circ} \mathrm{C} / 4 \mathrm{hours}$
$954^{\circ} \mathrm{C} / 1 \mathrm{hr} / 7738^{\circ} \mathrm{C} / 2 \mathrm{hr}, \mathrm{FC}$ to
$650^{\circ} \mathrm{C}+650^{\circ} \mathrm{C} / 8 \mathrm{hr}{ }^{*}$
$760^{\circ} \mathrm{C} / 500 \mathrm{hr}+$ Creep tested
a $706^{\circ} \mathrm{C} / 70 \mathrm{KSI} / 256 \mathrm{hr}$
$705^{\circ} \mathrm{C} / 1000 \mathrm{hr}$.
$732^{\circ} \mathrm{C} / 2500 \mathrm{hr}$.


*Standard Alloy 718 Plus heat treatment.

\section{Metallography of Alloy 718 Plus $^{\text {TM }}$}

\section{A. Electropolishing}

The choice of either a mechanical or electrolytic polish for Alloy 718 Plus $^{\mathrm{TM}}$ depends on the size and type of phases present. It is difficult to remove all of the flow layer present on a mechanically polished surface and still reveal fine $\gamma^{\prime}$ precipitation using a $\mathrm{HCl}$ containing etchant solution. This type of problem is overcome by electropolishing since no flow layer is formed by electropolishing.

All the samples were ground through 6 micron diamond paste and then electropolished for 10 seconds in a $20 \% \mathrm{H}_{2} \mathrm{SO}_{4}$-methanol solution at 25 volts. During polishing, the samples were agitated to remove the surface residue.

The structures produced by electropolishing are first studied optically since there is a selective attack on various phases. Carbides, borides and oxides will be in relief while $\gamma^{\prime}, \gamma^{\prime \prime}$, and delta phases will be polished flat in the plane of the matrix. Although electropolished samples can be studied on the SEM, the structures in the samples need to be etched for greater contrast.

\section{B. Etching of Alloy $718 \mathrm{Plus}^{\mathrm{TM}}$}

To reveal the $\gamma^{\prime \prime}, \gamma^{\prime}$, and/or delta phases, the electropolished samples are electro-etched in a solution composed of $170 \mathrm{cc} \mathrm{H}_{3} \mathrm{PO}_{4}+10 \mathrm{cc} \mathrm{H}_{2} \mathrm{SO}_{4}+15$ grams of $\mathrm{CrO}_{3}$ at 5 volts for 8 seconds. In addition to putting the $\gamma^{\prime}, \gamma^{\prime \prime}$ and delta phases in relief, the $\mathrm{CrO}_{3}$ etch will preferentially attack $\mathrm{Cr}$ rich phases like $\alpha \mathrm{Cr}$ and sigma phase. The delta phase and grain boundaries can be accentuated without the presence of $\gamma^{\prime}$ by electro-etching samples in a $15 \% \mathrm{HCl}$-methanol solution. The delta phase of each sample in this study was prepared in this manner as well by the $\mathrm{CrO}_{3}$ technique.

\section{Structural Results}

\section{$\gamma^{\prime}$ Phase}

The $\gamma^{\prime}$ solvus in alloy $718 \mathrm{Plus}^{\mathrm{PM}}$ is $954^{\circ} \mathrm{C}$ as reported by $\mathrm{CaO}(1)$. The amount of $\mathrm{Al}+\mathrm{Ti}$ in alloy 718 Plus ${ }^{\mathrm{PM}}$ should give a $\gamma^{\prime}$ solvus of $982^{\circ} \mathrm{C}$. The decrease in $\gamma^{\prime}$ solvus temperature of alloy 718 Plus is probably due to the presence of the $10 \% \mathrm{Fe}$.

The size of the $\gamma^{\prime}$ in alloy 718 Plus $^{\mathrm{PM}}$ which has been given a $760^{\circ} \mathrm{C}$ age is very small, probably less than $200^{\circ} \mathrm{A}$, and a magnification of $30,000 \mathrm{X}$ is necessary to detect it. If the 718 Plus is aged at $760^{\circ} \mathrm{C}$ or lower for extended times, the $\gamma^{\prime}$ grows and is more easily seen. In order to follow the changes of the $\gamma^{\prime}$ in the different samples, all of the $\gamma^{\prime}$ pictures will be shown at $30,000 \mathrm{X}$ in this paper.

Figure 1a shows the $\gamma^{\prime}$ precipitation in the as heat treated condition $(954 * \mathrm{C} / 1 \mathrm{hr}+$ $788^{*} \mathrm{C} / 2 \mathrm{hr}, \mathrm{FC}$ to $650 \mathrm{C}$ and hold for $8 \mathrm{hrs}$ at $650^{\circ} \mathrm{C}$ ). If the samples is D.A. (direct aged) heat treated and exposed for 100 hours at $760^{\circ} \mathrm{C}$ the $\gamma^{\prime}$ also is very small. Figure $1 \mathrm{~b}$. If the alloy 718 Plus is heat treated below the $954^{\circ} \mathrm{C} \gamma^{\prime}$ solvus temperature, a large $\gamma^{\prime}$ precipitate will form and a smaller $\gamma^{\prime}$ will precipitate during the $760^{\circ} \mathrm{C}$ age as seen in Figure 2a. When the alloy is exposed 


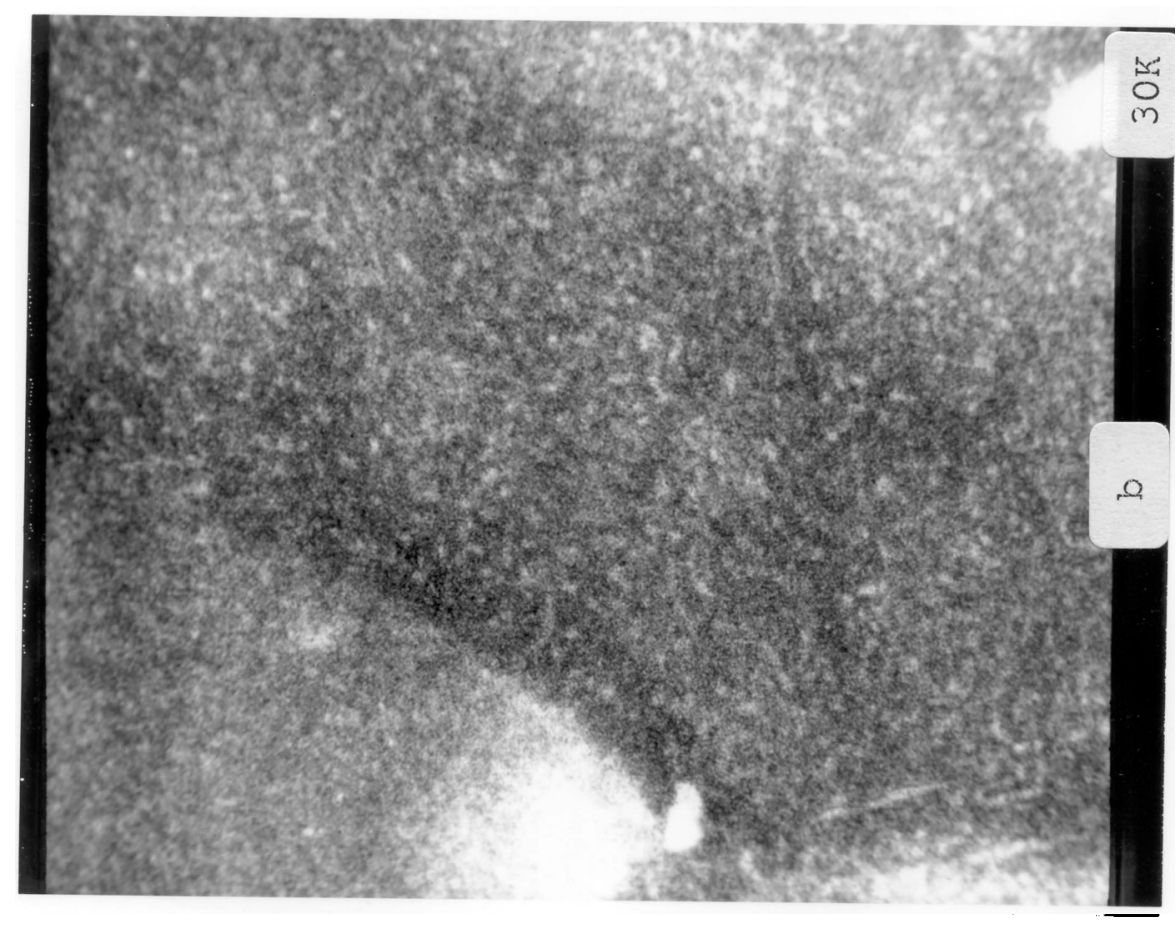

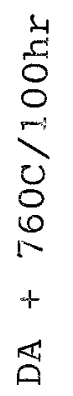

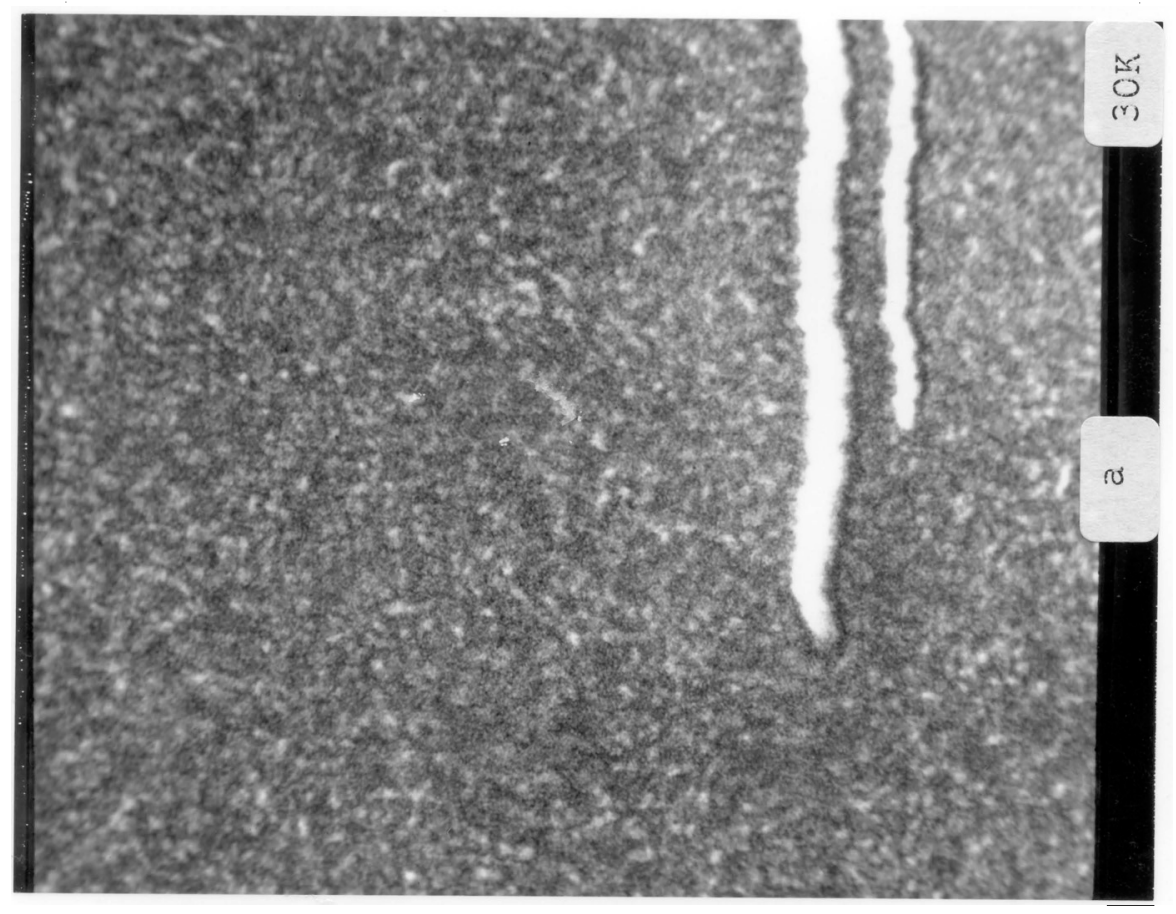

0
0
4
0
01
4
0
+1
0
0
0
04
0
0
4 


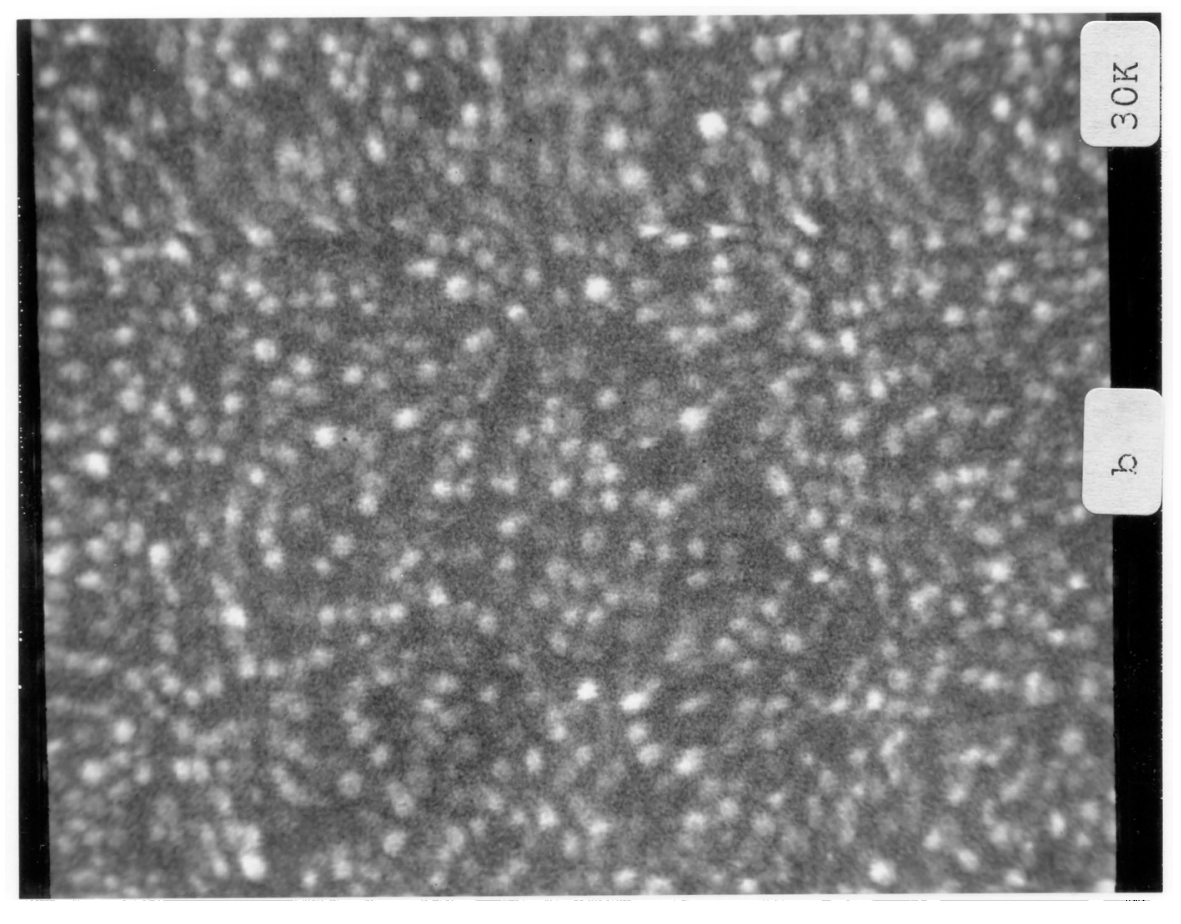

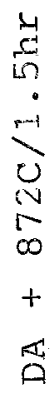

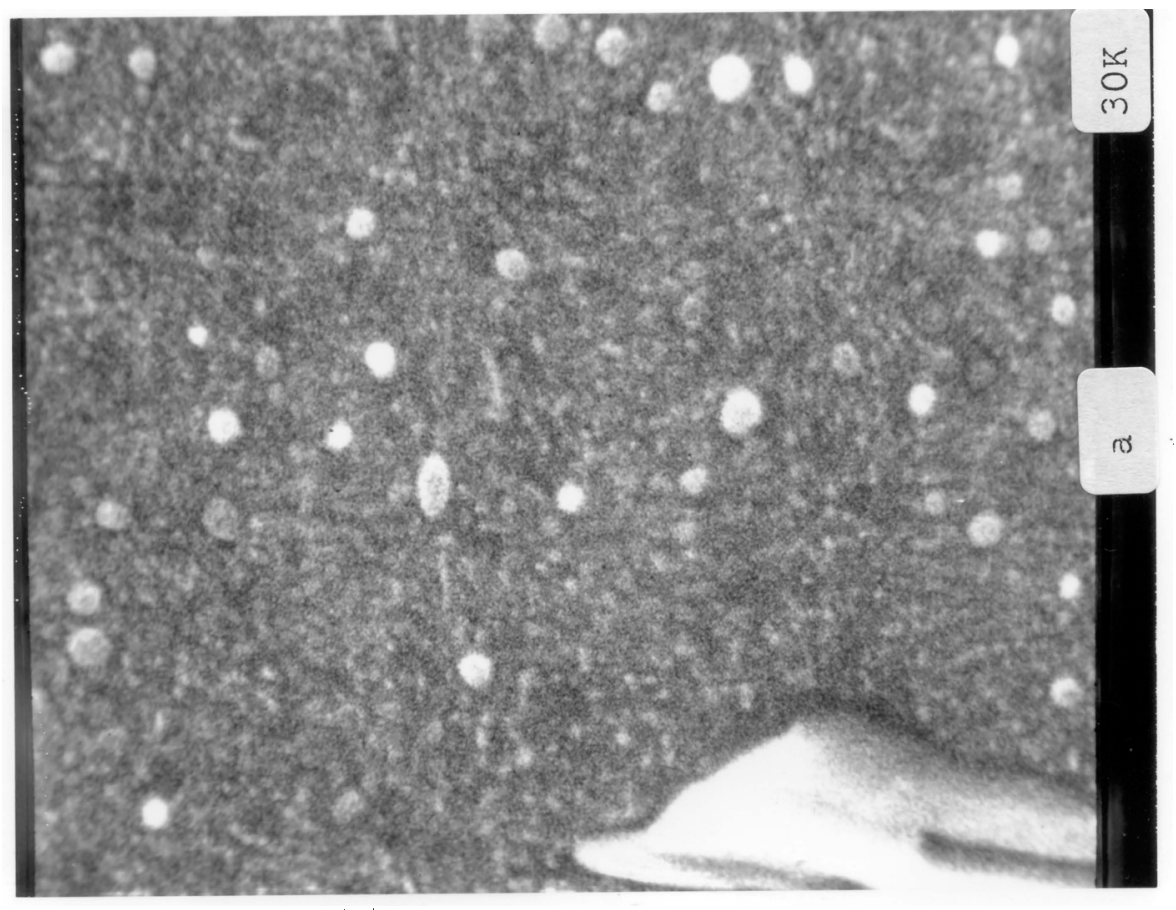

堅

0
0
5
5
-1
0
02
2
3
0
0 

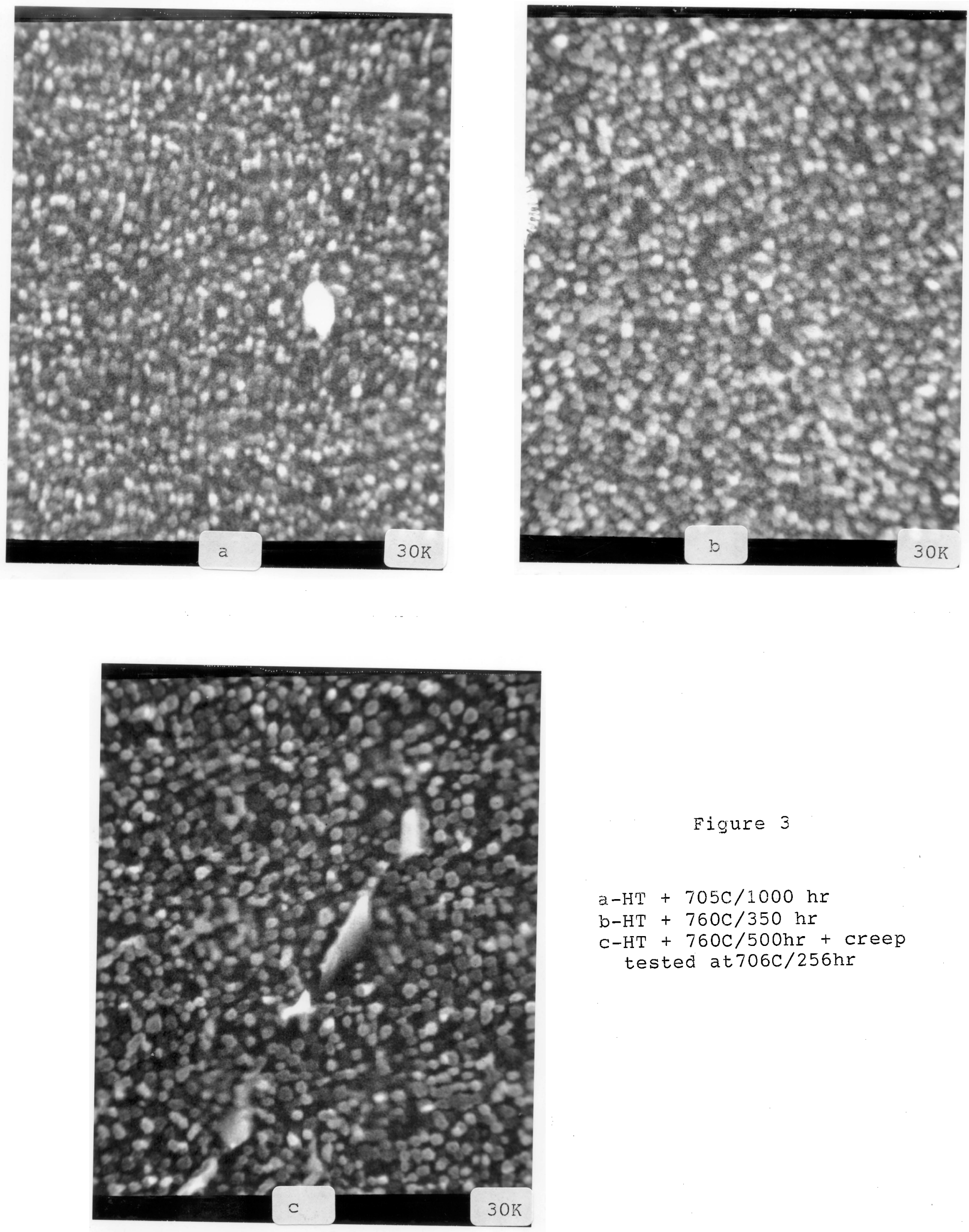

Figure 3

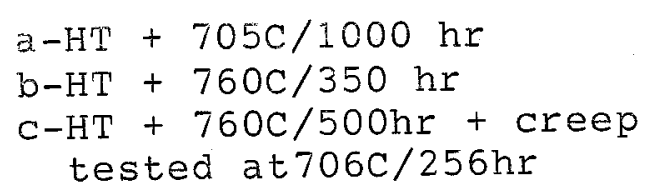




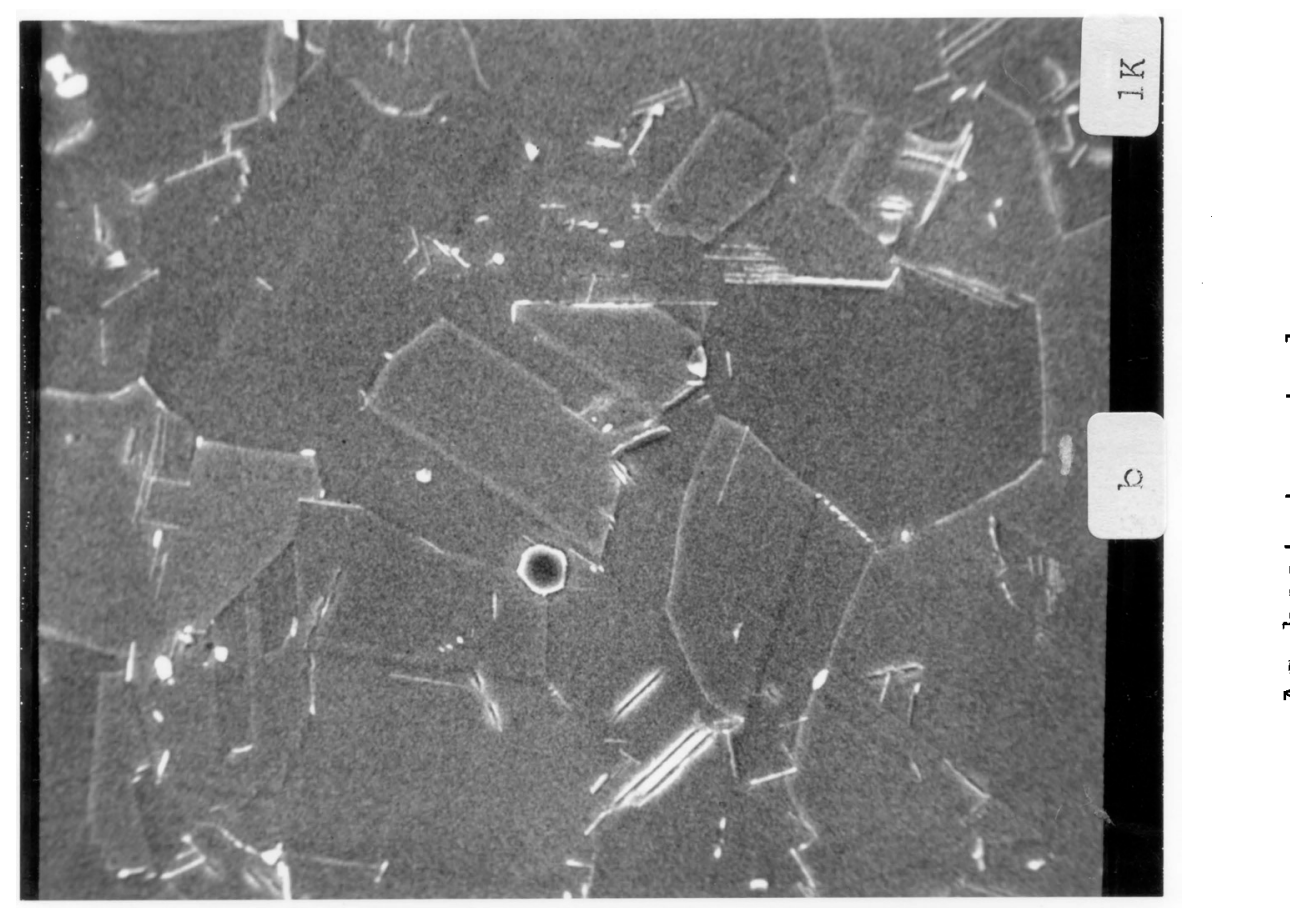

0
0
0
0
0
0
4
+3
+3
0
0
0
0
0
0

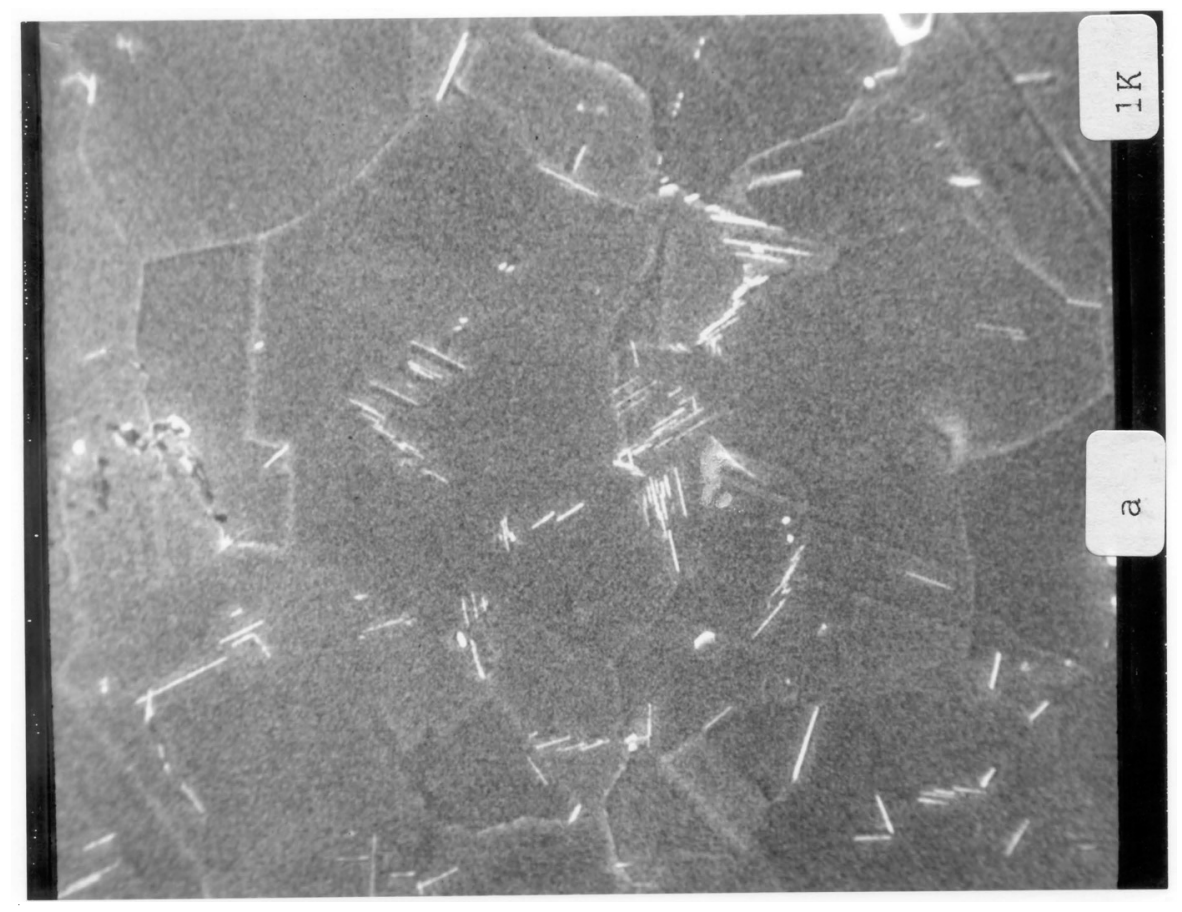

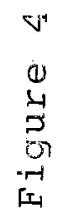

4
0
0
0
$N$
0
0 


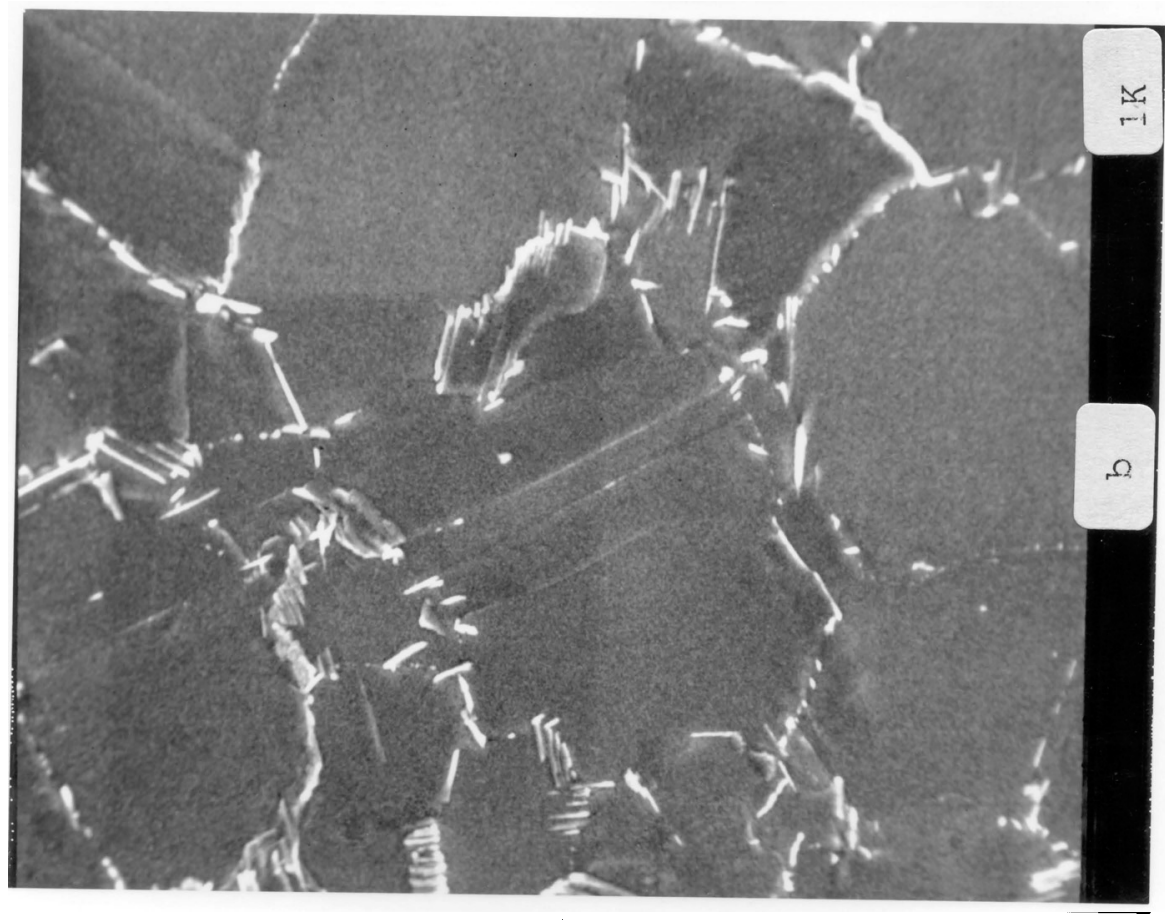

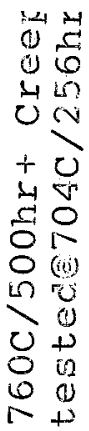

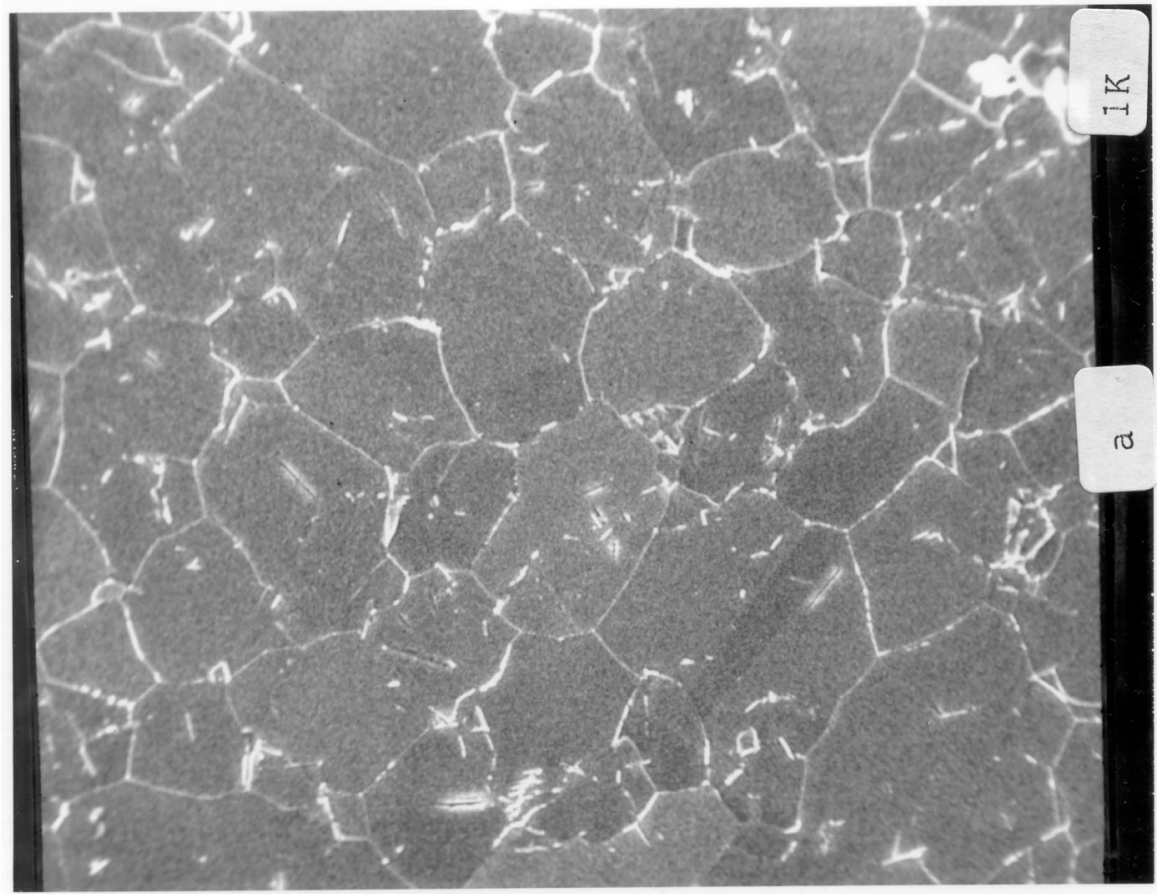

in

0
4
3
01
-11
11

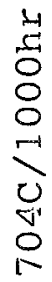


at some intermediate temperature such as $872^{\circ} \mathrm{C}$, an intermediate $\gamma^{\prime}$ size will form at the temperature as seen in Figure 2b. Figure 3 shows the resultant $\gamma^{\prime}$ in samples exposed for an extended time at $705^{\circ} \mathrm{C}$ and shorter times at $760^{\circ} \mathrm{C}$. There is no evidence of $\alpha \mathrm{Cr}$ or sigma phases in the samples.

\section{B. Delta Phase}

The high $\mathrm{Nb}$ contents in both alloys 718 and alloy 718 Plus forms a delta phase at the grain bounbdaries which is used to control grain size during processing into the desired shapes. It is well known that delta phase in the grain boundaries is beneficial for notch ductility.

To more readly follow the delta phase in the alloy 718 Plus, the samples were re-prepared using an electro-etch in 10\% HCl-methanol which dissolves away the $\gamma^{\prime}$ phase and leaves the delta in relief. Thus, the delta phase can be readily examined at magnification of $1000 \mathrm{X}$ to $3000 \mathrm{X}$.

Figure $4 \mathrm{a}$ shows the residual delta left from processing after a 4 hour solution at $982^{\circ} \mathrm{C}$. Figure $4 \mathrm{~b}$ shows the delta phase after the standard heat treatment. Because only a small amount of fine $\gamma^{\prime}$ forms during the standard heat treatment, only a small amount of delta phase forms.

Figure 5a shows more delta phase at the boundaries as the material is exposed for 1000 hours at $704^{\circ} \mathrm{C}$. However, if the alloy 718 Plus is exposed at $760^{\circ}$ for 500 hours and then creep tested at $704^{\circ} \mathrm{C}$ for 256 hours, a greater amount of delta has grown as seen in Figure $5 \mathrm{~b}$.

\section{Longtime Exposure at $732^{\circ} \mathrm{C}$}

A sample of alloy 718 Plus was exposed at $732^{\circ} \mathrm{C}$ for 2500 hours to follow the growth of $\gamma^{\prime}$ and delta phases and to note the possible formation of any other secondary phases. Figure $6 a$ shows that the $\gamma^{\prime}$ and delta phases have grown such that they can be seen at $10,000 \mathrm{X}$. When the $\gamma^{\prime}$ is magnified $30,000 \mathrm{X}$, it appears that the main $\gamma^{\prime}$ is about $2000 \AA$ and there are a number of $\gamma^{\prime}$ sizes as seen in Figure 6b. Figure 6c shows that the extracted $\gamma^{\prime}$ residue also contains various size $\gamma^{\prime}$ s.

Figure 7a shows that a great amount of delta phase has formed after 2500 hours at $732^{\circ} \mathrm{C}$. When the phases in the sample are extracted in ammonium sulphate and citric acid in water, both the delta phase left in the matrix and the extracted delta show $\gamma^{\prime}$ clinging to the delta plates, Figures $7 \mathrm{~b}$ and $7 \mathrm{c}$.

\section{$\underline{\text { X-ray Diffraction Results }}$}

A limited amount of phase extractions were carried out to confirm the nature of phases in Alloy 718 Plus. The $\gamma^{\prime}$ was extracted using a solution of 1 gram ammonium sulphate +1 gram of citric acid in water while the inert phases were extracted in a $10 \% \mathrm{HCl}$-methanol solution. Delta phase was present in the inert phase extraction as well as a primary $\mathrm{MC}$ with a lattice parameter of $4.43^{\circ} \mathrm{A}$. Gamma prime was found to be present in the as-heat treated condition as well as in the 2500 hour exposure at $705^{\circ} \mathrm{C}$. No $\gamma^{\prime \prime}$ was present in the as heat treated condition nor was any $\alpha \mathrm{Cr}$ found after long time exposure. 

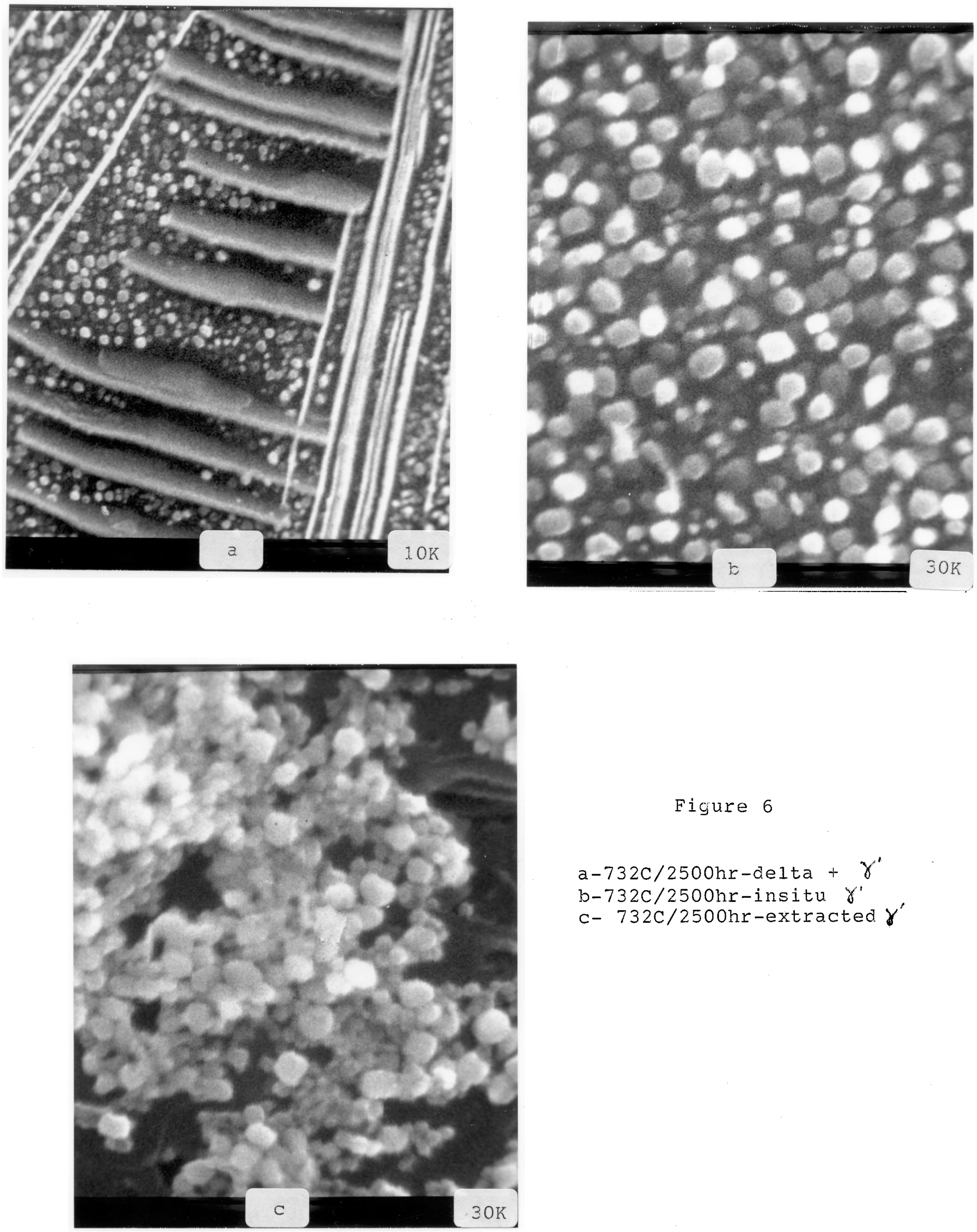

Figure 6

$a-732 \mathrm{c} / 2500 \mathrm{hr}-\mathrm{delta}+\gamma^{\prime}$

b-732C/2500hr-insitu $\gamma^{\prime}$

$c-732 \mathrm{C} / 2500 \mathrm{hr}$-extracted $\gamma$ 

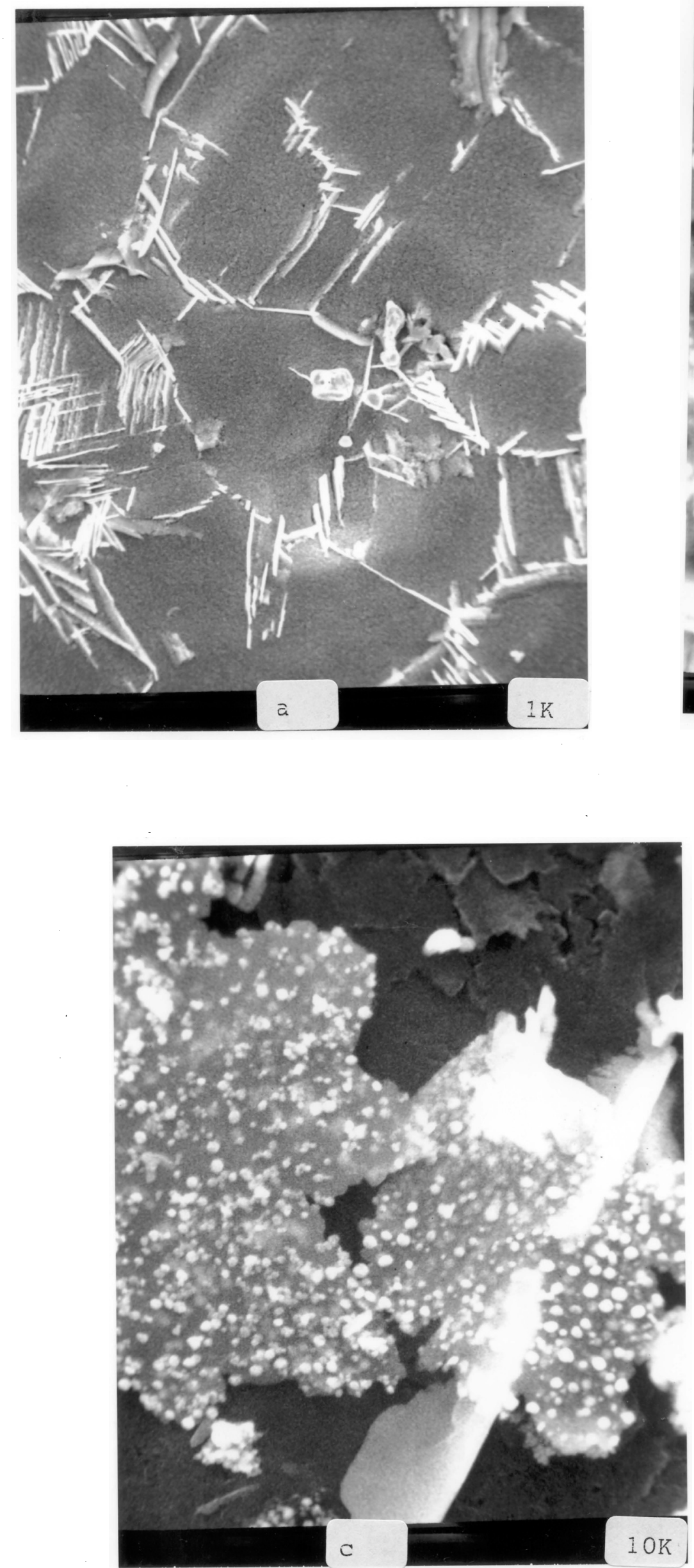

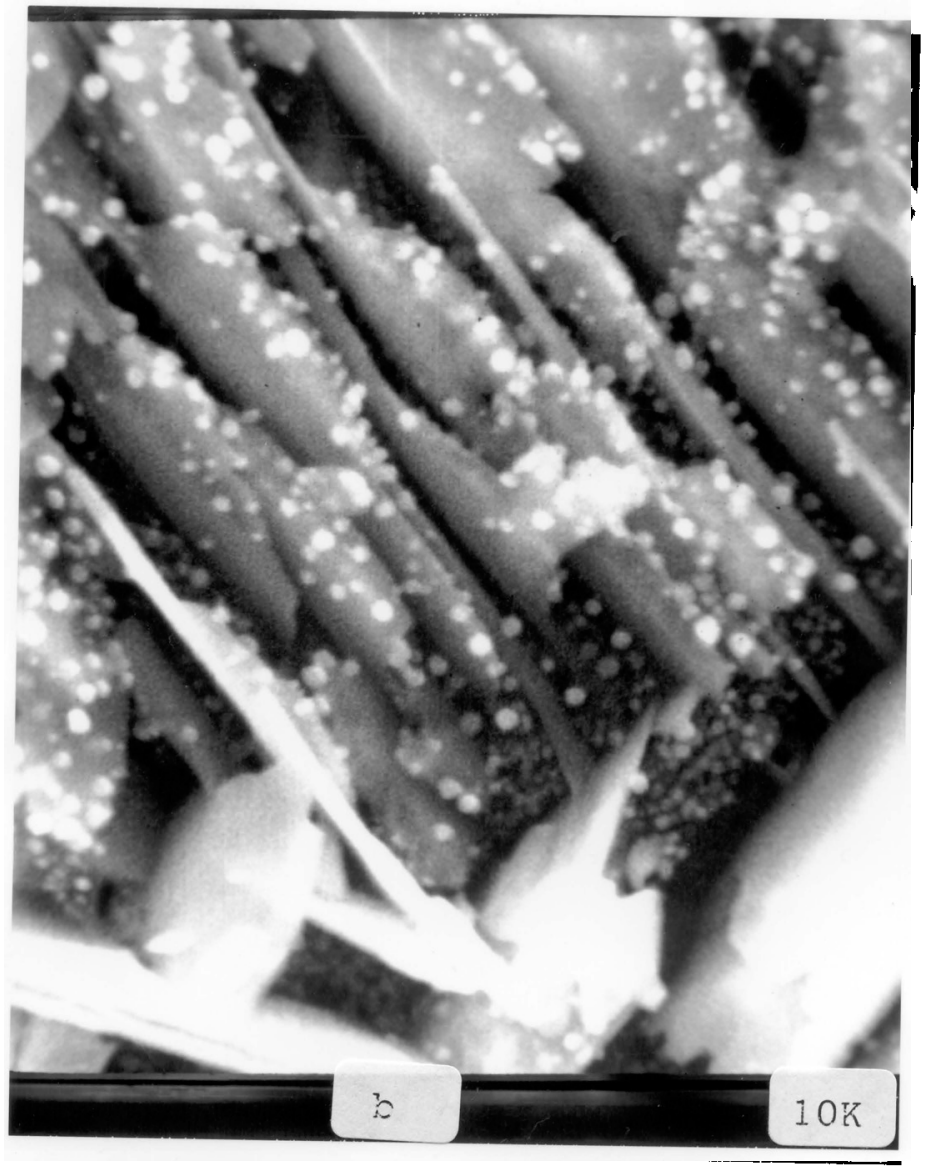

Figure 7

a $-732 \mathrm{c} / 2500 \mathrm{hr}-$ de1ta

b-732C/2500hr-delta plates

c-732C/2500hr-extracted delta 


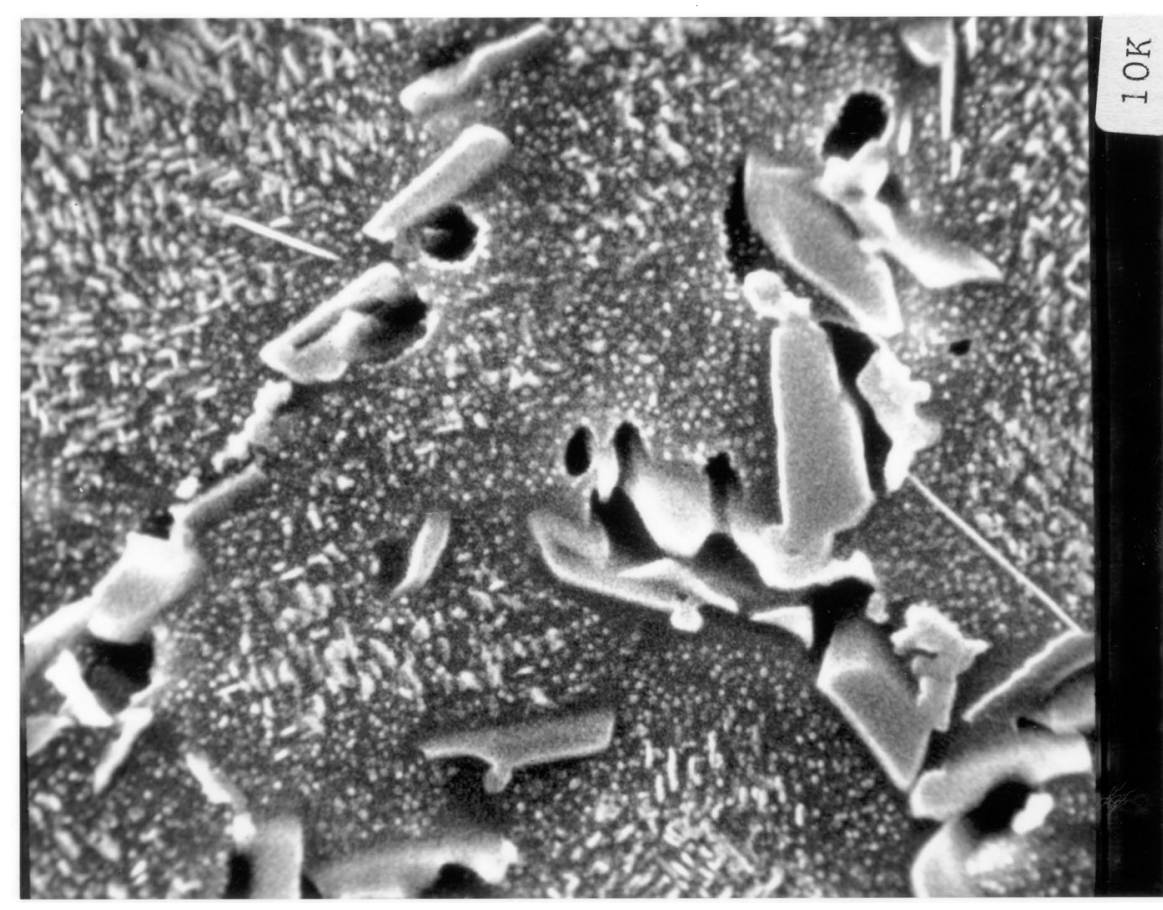

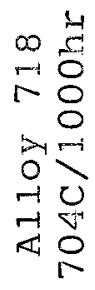

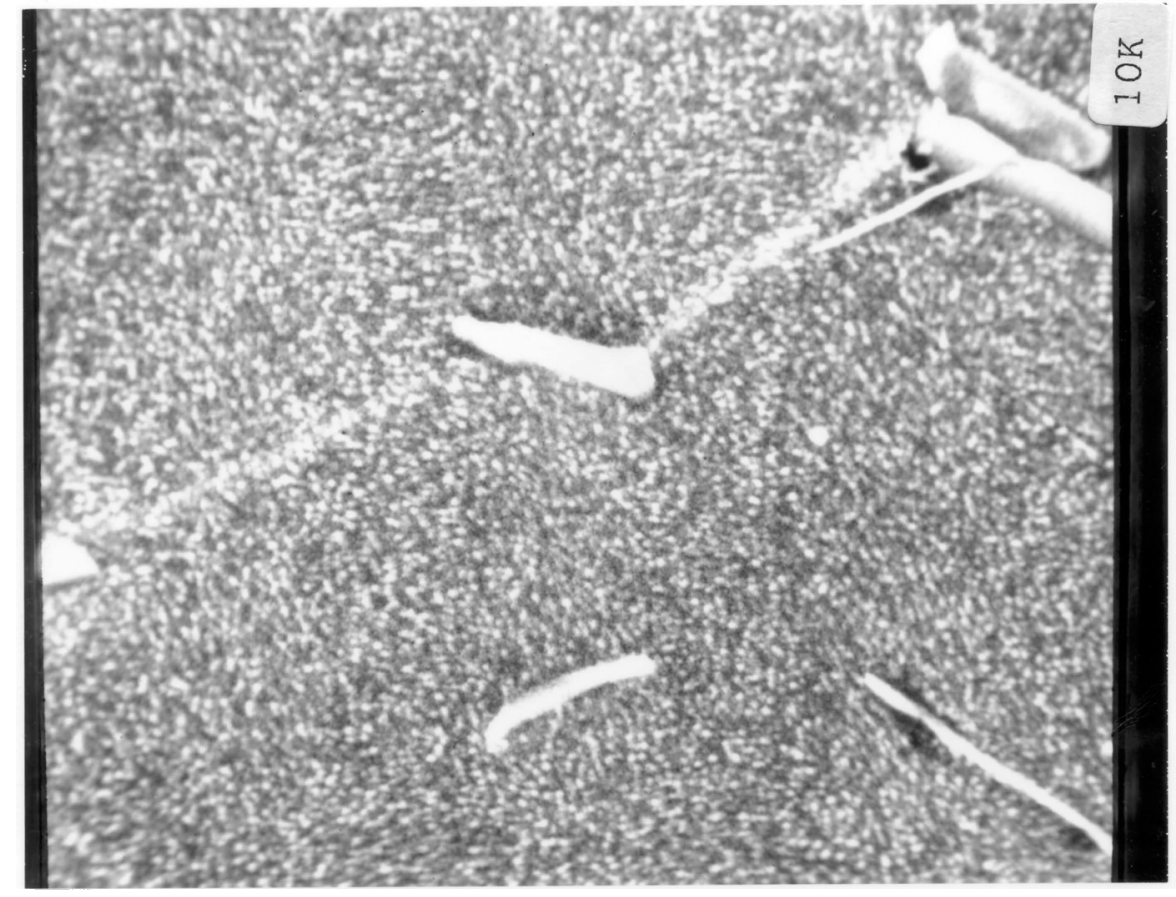

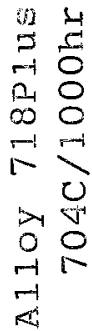




\section{EDAX Study}

Some of the residue used for x-ray analysis was placed on a carbon stub and probed in the SEM. The $\gamma^{\prime}$ and delta particles showed high Nb contents. A typical analysis would be 53.8 $\mathrm{Ni}, 4 \mathrm{Fe}, 4.6 \mathrm{Co}, 3.6 \mathrm{Cr}, 8.1 \mathrm{Ti}, 17.4 \mathrm{Nb}$ and $8.9 \mathrm{Al}$. Similar compositions for $\gamma^{\prime \prime}$ and delta were found in alloy 625 by Cozer (2). No evidence was found of particles containing high $\mathrm{Cr}$ contents to signify the presence of $\alpha \mathrm{Cr}$ or sigma phases.

\section{Conclusions}

The metallographic study shows the $\gamma^{\prime}$ and delta phases to be the main phases in alloy 718 Plus. The $\gamma^{\prime}$ and delta phases continue to grow with increased time of exposure. The $\gamma^{\prime}$ size in the as heat treated condition is less than $200 \AA$ while in longtime exposures at $732^{\circ} \mathrm{C}$, the $\gamma^{\prime}$ size may be $2000 \AA$ or larger.

There is no evidence of $\alpha \mathrm{Cr}$ formation by metallographic, $\mathrm{X}$-ray analysis, or EDAX study in samples exposed for 2500 hours at $732^{\circ} \mathrm{C}$.

While alloy 718 undergoes changes in the $\gamma^{\prime \prime}$ and the formation of $\alpha \mathrm{Cr}$ when exposed at $704^{\circ} \mathrm{C}$ for 1000 hours, alloy 718 Plus continues to exhibit a stable microstructure as seen in Figure 8 .

\section{Acknowledgements}

The authors would like to thank the Reference Metal Company and the ATI Allvac Company for their financial support for this study. Technical discussions with Dr. Wei-Di $\mathrm{CaO}$ have been most helpful.

\section{References}

1. W. D. Cao and R. L. Kewnnedy, Superalloys 2004, TMS.

2. R. Cozar et al., Superalloys 718, 625, and Various Derivatives, ed. E. A. Loria, 1991, 423-436. 